DOI: $10.12957 /$ demetra.2015.17328

\title{
Análise microbiológica dos sorvetes self-service sabor chocolate da cidade de Sinop-MT
}

\author{
Microbiological analysis of self-service ice cream chocolate flavor in Sinop-MT, Brazil
}

Josiane Miranda de Souza'

Elizabeth Cristina Gomes dos Santos²

Naira Josele Neves de Brito?

Gabriel Araújo da Silva ${ }^{3}$

1 Universidade de Cuiabá (Unic Sinop Aeroporto). Sinop-MT, Brasil

2 Universidade Federal do Rio Grande do Norte, Programa de Pós-graduação em Ciências da Saúde. Natal-RN, Brasil.

${ }^{3}$ Universidade Federal do Rio Grande do Norte, Laboratório Multidisciplinar. Natal-RN, Brasil.

Correspondência / Correspondence

Gabriel Araújo da Silva

E-mail:prof.gabriel.araujo@gmail.com

\section{Resumo}

O sorvete é uma sobremesa gelada, originária da China, preparada com uma mistura de neve, frutas e suco de frutas. O produto é consumido em regiões de clima quente, por ser refrescante, de sabor agradável e composição nutricional variável. No modelo de venda direta ao consumidor, ou self-service, o sorvete está exposto a condições sanitárias inadequadas, oriunda de contaminação por saliva e outras secreções dos próprios consumidores. $\mathrm{O}$ presente trabalho objetivou realizar análise microbiológica dos sorvetes sabor chocolate, das sorveterias self-service de Sinop-MT. Foram coletadas amostras de cinco estabelecimentos em pontos aleatórios, com posterior análise em duplicata. A partir das análises microbiológicas, foram observados resultados positivos para Salmonella sp. em nove amostras. A presença de coliformes totais, termotolerantes e Escherichia coli foi confirmada em todas as amostras. Todavia, nenhuma amostra apresentou resultados positivos para bolores ou leveduras psicrotróficos. No contexto geral, as amostras estão em condições insatisfatórias, oferecendo risco à saúde dos consumidores, sendo necessárias medidas para o controle na prevenção de contaminação.

Palavras-chave: Sorvete. Coliformes Totais. Coliformes Termotolerantes. Fungos Psicrotróficos. Perfis Sanitários.

\section{Abstract}

Ice cream is a frozen dessert that was created through a mixture of snow, fruit and fruit juice originated in China. This product is consumed in warm climates, being refreshing, pleasant taste and 
nutritional composition variable. In direct sales to consumers, or self-service model, the ice cream is exposed to inadequate sanitary conditions, derived from contamination by saliva and other secretions of consumers. This study aimed to perform microbiological analysis of chocolate ice cream flavor, the selfservice ice cream Sinop-MT, Brazil. Samples from five sites were collected at random points soon after the analysis performed in duplicate. From the microbiological analysis can observe positive for nine samples of Salmonella sp. The presence of total coliform bacteria, thermotolerant and E. coli was confirmed in all samples. However, no sample tested positive for mold or yeast. In general, the samples are in poor condition, offering health risk for consumers. Therefore, you should take steps to control to prevent contamination.

Key words: Ice Cream. Total Coliforms. Fecal Coliforms. Psychrotrophic Fungi. Sanitary Profiles.

\section{Introdução}

A criação de sobremesas geladas iniciou-se com a mistura de neve, frutas e suco de frutas. Essa antiga prática culinária provavelmente é originária da China. As sobremesas geladas foram introduzidas na Europa no final do século XIII, mas somente a aristocracia era consumidora dessa iguaria, que se espalhou pelo mundo no período das grandes colonizações. ${ }^{1}$

Dentre as sobremesas geladas, o sorvete merece destaque, sendo caracterizado como um produto alimentício formado basicamente por uma mistura de gorduras e proteínas, com ou sem adição de outros ingredientes, em grande maioria substâncias que tenham sido submetidas ao congelamento e que necessitam permanecer congeladas para sua conservação. Portanto, são necessárias garantias de que o produto será conservado e mantido no estado congelado ou parcialmente congelado nas etapas de armazenamento, transporte e entrega ao consumidor. ${ }^{2}$

Os sorvetes são produtos relativamente seguros, devido ao processo de pasteurização, porém a contaminação depois deste processo não está isenta. Esse alimento é consumido principalmente em regiões de clima quente, por ser um alimento refrescante, de sabor agradável e de composição nutricional variável. Quando acrescidos de leite, esse produto se torna mais suscetível à contaminação por micro-organismos diversos devido à fermentação da lactose, por manipulação e armazenamento de forma inadequada e pelo contato direto com o cliente em self service. ${ }^{3}$ 
No modelo de venda direta ao consumidor, ou self service, o sorvete está exposto a condições sanitárias inadequadas, como contato com o ar e água utilizada para o acondicionamento das colheres, e contaminação por saliva e outras secreções oriundas dos consumidores. Assim, os fabricantes de sorvete não podem considerar apenas o processo de pasteurização e congelamento suficiente para a não contaminação e proliferação dos micro-organismos patogênicos. ${ }^{4}$

A maioria dos consumidores não associa que o sorvete possa apresentar riscos de natureza microbiológica, pois julgam que a baixa temperatura assegure sua inocuidade. Todavia, o congelamento do produto não inibe a presença de micro-organismos patogênicos resistentes a baixas temperaturas, chamados de psicrotróficos, e que podem ser ingeridos pelos consumidores. ${ }^{5}$

Diversos grupos de micro-organismos têm a capacidade de crescer no sorvete, devido às condições ideais encontradas. Em consequência da demanda do comércio que atende a todo e qualquer público, é essencial o alerta para qualquer tipo de risco que esteja relacionado ao consumo de alimentos. Assim, outros grupos microbianos envolvidos em contaminação alimentares, como os coliformes totais e fecais, também podem estar presentes no sorvete. ${ }^{6}$

Dentre os sabores disponíveis, o sorvete de chocolate é um alimento popular e de grande consumo, em todas as idades, principalmente pelas crianças. Desse modo, a qualidade deste alimento é de extrema importância para garantia de sua segurança, bem como para a saúde da população. $^{7}$

Portanto, este trabalho teve como objetivo realizar a análise microbiológica dos sorvetes sabor chocolate, das sorveterias self service de Sinop-MT, analisando a presença de coliformes totais, termotolerantes, Salmonella sp., Escherichia coli, bolores e leveduras.

\section{Metodologia}

Foram obtidas dez amostras de sorvete sabor chocolate de cinco sorveterias self-service da cidade de Sinop-MT, em pontos aleatórios, no mês de maio de 2014. As amostras foram coletadas em frascos estéreis, e armazenadas em caixa térmica para o transporte até o laboratório de microbiologia da UNIC, onde foi realizada análise imediata. As análises foram feitas em duplicatas.

Foi utilizada a técnica do Número Mais Provável (NMP) para estimar a contagem de microorganismos dos grupos coliformes totais e termotolerantes. A técnica do NMP é uma forma de se estimar o número de micro-organismos presentes na amostra. É baseado na probabilidade estatística de certo número de micro-organismos estarem presentes na amostra quando uma quantidade ou soma de resultados positivos ocorrem pela inoculação de alíquotas dessa amostra em uma série de tubos, contendo um meio de cultura líquido adequado ao seu crescimento. ${ }^{8}$ 
Assim, pesaram-se assepticamente 25g de cada amostra, que foi transferida para um Erlenmeyer contendo $225 \mathrm{ml}$ de salina $\left(10^{-1}\right)$, com posterior homogeneização. Para o teste presuntivo de coliformes totais, diluições decimais a partir da diluição $10^{-1}$ foram preparadas, pipetando 0,1 ; $1 \mathrm{e}$ $10 \mathrm{ml}$ da amostra em uma série de três tubos contendo $9,0 \mathrm{ml}$ de caldo lactosado em concentração dupla e tubos de Durham invertidos, incubados a 35 C durante 24 e 48 horas. Após esse período, os tubos que apresentaram turvação e produção de gás no seu interior foram considerados positivos. Para o teste confirmativo de coliformes totais, transferiu-se uma alçada de cada tubo positivo com caldo lactosado para outros tubos contendo caldo verde brilhante (CLBVB), incubados a 35드 por 48 horas. Os resultados dos tubos positivos foram expressos na tabela do NMP de coliformes totais por grama da amostra do sorvete. ${ }^{9}$

Para confirmação da presença de coliformes termotolerantes, foram repicados dos tubos de CLBVB, indicando a presença de coliformes totais, para tubos contendo caldo EC, incubados a 45ํㅡ por 48 horas, em banho-maria. Para a contagem de E.coli, os tubos de caldo EC com produção de gás foram repicados e semeados em placas contendo ágar eosina azul de metileno (EMB), incubadas a 35ํㅡ por 24 horas, para observação de crescimento ou não de colônias de E.coli.

Na pesquisa de Salmonella sp., realizou-se o repique de cada amostra com produção de gás dos tubos contendo CLBVB em ágar Salmonella Shigella (SS), incubados por 24 ha 35ㄷ․

Para bolores e leveduras, foram diluídos $25 \mathrm{~g}$ do sorvete em $225 \mathrm{ml}$ de solução fisiológica, adquirindo a primeira diluição $10^{-1}$. Transferiu-se $1 \mathrm{ml}$ para um tubo contendo $9 \mathrm{ml}$ de solução fisiológica, obtendo a diluição $10^{-2}$ e deste retirando $1 \mathrm{ml}$ para o segundo tubo de diluição $10^{-3}$. Alíquotas de $0,1 \mathrm{ml}$ das diluições $10^{-2}$ e $10^{-3}$ da amostra dos sorvetes foram semeadas e espalhadas em superfície, com o auxílio da alça de Drigalsky, em placas de Petri contendo ágar sabouraud acrescido de clorafenicol. Incubou-se a $10 \pm 3^{\circ} \mathrm{C}$ durante 14 e 21 dias, para pesquisa de fungos psicrotróficos. $^{5}$

\section{Resultados e discussão}

Os resultados obtidos para Salmonella sp., coliformes totais e termotolerantes, E.coli, bolores e leveduras pesquisadas nas amostras dos sorvetes de chocolate estão apresentados na tabela 1 . 
Tabela 1. Resultados das análises microbiológicas dos sorvetes sabor chocolate das sorveterias self-service de Sinop-MT, coletados em maio de 2014.

\begin{tabular}{lccccc}
\hline Amostra & $\begin{array}{c}\text { Salmonella } \\
\text { sp. }\end{array}$ & $\begin{array}{c}\text { Coliformes } \\
\text { Totais } \\
(\mathrm{NMP} / \mathrm{g})\end{array}$ & $\begin{array}{c}\text { Coliformes } \\
\text { termotolerantes } \\
(\mathrm{NMP} / \mathrm{g})\end{array}$ & $\begin{array}{c}\text { Escherichia } \\
\text { coli } *\end{array}$ & $\begin{array}{c}\text { Bolores e } \\
\text { leveduras }\end{array}$ \\
\hline 1A & + & 1100 & 460 & + & - \\
1B & + & 460 & 240 & + & - \\
2A & + & 150 & 43 & + & - \\
2B & + & 28 & 3,6 & + & - \\
3A & + & 64 & 43 & + & - \\
3B & + & 75 & 38 & + & - \\
$4 \mathrm{~A}$ & + & 43 & 15 & + & - \\
$4 \mathrm{~B}$ & - & 15 & 9,2 & + & - \\
$5 \mathrm{~A}$ & + & 240 & 120 & + & - \\
$5 \mathrm{~B}$ & + & 210 & 160 & + & + \\
\hline
\end{tabular}

* Teste confirmativo; (+) Presença; (-) Ausência.

Na tabela 1, os resultados obtidos para Salmonella sp. demonstraram que nove das dez amostras no meio SS tiveram crescimento de colônias incolores, não fermentadoras de lactose, ou seja, houve a presença de Salmonella sp. em 25 g do sorvete. De acordo com a RDC n ${ }^{\circ}$ 12/01, que trata dos padrões microbiológicos sanitários para alimentos e estabelece a ausência da bactéria Salmonella sp., as amostras não atenderam às normas da Agência de Vigilância Sanitária (ANVISA). ${ }^{2}$

Na pesquisa de Salmonella, este trabalho obteve resultado semelhante à pesquisa de Oliveira et al., ${ }^{10}$ que avaliou a qualidade microbiológica dos sorvetes comercializados nos principais supermercados de Maceió-AL, sendo que em todas as amostras foi atestada a presença de Salmonella sp. Dado também observado por Silveira et al., ${ }^{11}$ em sua avaliação físico-química e microbiológica de sorvetes do tipo tapioca, que mostraram a presença de Salmonella sp. em 75\% das amostras. E, segundo Hoffmann et al., ${ }^{12}$ após análises da qualidade higiênico-sanitária de sorvetes na cidade de São José do Rio Preto-SP, 75\% das amostras indicaram contaminação por Salmonella sp. 
Salmonella sp. são bactérias gram negativas, não esporuladas, patogênicas e não fermentadoras de lactose. Seu reservatório natural é o intestino do homem e outros animais, principalmente aves. Em geral, moscas e baratas são veículos de disseminação destas bactérias. ${ }^{13}$

Doenças alimentares, entre elas a salmonelose, resultam da ingestão de alimentos contaminados por fezes. Outra doença, entre as mais graves causadas por Salmonella, é a febre tifoide, causada pela $S$. Typhimurium, que acomete somente o homem e não possui reservatórios em outros animais. Normalmente, a forma de disseminação da infecção é interpessoal e através da água e alimentos contaminados com material fecal humano. Essa doença tem o maior tempo de incubação, produz febre, vômitos, diarreia e septicemia. A febre paratifoide ou entérica,

forma mais branda que a tifoide, pode evoluir para septicemia e frequentemente desenvolver um quadro de gastroenterite, febre e vômitos. A Salmonella sp. pode contaminar uma ampla variedade de alimentos, dos tipos que possuem alto teor de umidade, carboidratos, como carne bovina e suína, aves, ovos, e principalmente proteínas, como no leite e derivados utilizados no preparo do sorvete. ${ }^{14}$ Sendo assim, tais condições dos sorvetes analisados caracterizam o produto como potencialmente capaz de causar toxinfecção alimentar, sendo portanto impróprio para consumo.

Para os resultados de coliformes totais, todas as amostras apresentaram positivas. A RDC $\mathrm{n}^{\circ}$ $12 / 2001^{15}$ não estabelece valores-padrão para contagem dos coliformes totais, mas altas contagens de coliformes podem indicar má higienização pessoal, desde a manipulação até o consumidor. ${ }^{16}$ Os resultados obtidos para coliformes termotolerantes, as amostras 2A, 2B, 3A, 3B, 4A, e 4B se apresentaram dentro do limite exigido pela legislação. No entanto, as amostras 1A, 1B, 5A e 5B obtiveram seus valores acima dos padrões microbiológicos de $50 \mathrm{NMP}$ por grama de tolerância para amostra indicativa. E todas as amostras avaliadas foram positivas para E. coli quando semeadas em placas EMB, apresentando crescimento de colônias verde-brilhantes típicas para E. coli.

E. coli, membro da família Enterobacteriaceae, são enterobactérias que pertencem ao grupo dos coliformes termotolerantes. Normalmente, habitam o intestino humano e de outros animais de sangue quente, sendo que algumas cepas são patogênicas em crianças e adultos quando presentes em outras partes do corpo humano, como trato urinário ou meninges, podendo causar doenças, além de intoxicações alimentares. A contagem de E. coli é utilizada como o principal indicador de contaminação fecal, estabelecendo as condições higiênico-sanitárias dos alimentos. A contaminação de alimentos se dá sobretudo pelo contato do material fecal com os produtos alimentícios, de forma que pode acontecer no momento do processamento de matérias-primas de origem animal, da falta de higiene dos manipuladores e, principalmente, pela má higienização dos consumidores. ${ }^{3,17}$

Ao avaliar os resultados obtidos para coliformes totais, nove das dez amostras estão sob condições de higiene insatisfatórias, dentre elas a amostra 1A (1100 NMP/g), em condições inaceitáveis para consumo direto. Assim, é correto afirmar que nas amostras com elevadas contagens de coliformes 
totais a matéria-prima estava contaminada; a limpeza e sanitização do local de preparo do alimento foram inadequadas; ou houve contaminação pós-processamento. ${ }^{18}$

Os dados deste estudo foram comparados com os da pesquisa dos coliformes fecais ou termotolerantes realizada por Rizzo-Benato, ${ }^{19}$ que analisou 12 amostras de sorvetes e do leite usado na fabricação do produto. Nesse estudo, a presença de coliformes fecais no sorvete sabor creme estava dentro do padrão estabelecido pela legislação, e o de chocolate não, evidenciando que tais resultados eram esperados devido à alta contaminação da principal matéria-prima, o leite usado para a fabricação do sorvete de chocolate, diferindo do leite utilizado no preparo do sorvete de creme. Pode-se inferir, assim, que nas amostras analisadas no presente trabalho, a contaminação tenha se originado da matéria-prima utilizada.

Muitos outros estudos analisaram a qualidade higiênico-sanitária de sorvetes nas últimas décadas e constataram que a maioria das amostras apresenta resultados para coliformes fecais fora dos padrões da legislação. Demonstra-se, assim, a recorrente contaminação neste tipo de alimento, servindo de alerta para que as instituições competentes normatizem e fiscalizarem o processo produtivo, evitando riscos à saúde humana..$^{20-22}$

Não houve crescimento de bolores e leveduras para todas as amostras de sorvetes analisadas, ressalvando-se que o crescimento de bolores e leveduras avaliados neste trabalho ocorreu em baixa temperatura. Assim, é correto afirmar que não houve crescimento para cepas de fungos psicrotróficos. A legislação não oferece limites de contagem para bolores e leveduras, mesmo estes constituindo um grande grupo de micro-organismos, a maioria originária do solo ou do ar, que apresentam riscos à saúde.

A importância de determinar a presença de bolores e leveduras nas amostras se deve ao fato de os fungos produtores de micotoxinas serem graves agentes hepatocancerígenos. Todavia, a temperatura de acondicionamento do sorvete não é propícia ao crescimento de fungos, e normalmente essas micotoxinas não aparecem diretamente no sorvete, podendo ser conduzidas ao sorvete pelos elementos contidos na cobertura ou outros produtos à disposição dos clientes para o consumo dos sorvetes self-service. ${ }^{3}$

Os psicrotróficos são micro-organismos que crescem em alimentos sob refrigeração de 0 a 7º $\mathrm{C}$ no prazo de sete a dez dias, e alguns grupos de fungos se multiplicam em alimentos refrigerados, com baixa atividade de água, alta acidez ou condições de embalagem que inibam crescimento microbiano. ${ }^{9}$ Os autores Diogo et al. ${ }^{13}$ e Silveira et al. ${ }^{11}$ obtiveram, na maioria de suas análises de sorvete, a presença de fungos mesófilos. Portanto não houve relatos de pesquisas de sorvetes visando a análises de psicrotróficos. Desta forma, se tornou inviável a comparação dos resultados do presente estudo, uma vez que foram pesquisados fungos que têm seu crescimento em baixas temperaturas. 
A contaminação dos alimentos pode acontecer por vários fatores, começando pelo preparo do alimento, má higienização dos manipuladores, equipamentos, utensílios, ambiente, transporte e condições inadequadas de armazenamento. E, após a etapa de aquisição, preparação e industrialização, os alimentos continuam expostos à contaminação nos centros de distribuição, seja em supermercados, restaurantes ou residências. ${ }^{18}$

O sistema de distribuição do tipo self-service tem aumentado o índice de contaminação dos alimentos pelos consumidores, uma vez que estes mantêm contato direto com os alimentos expostos no balcão de distribuição. ${ }^{3,23}$

Pesquisa realizada por Medeiros et al. ${ }^{24}$ avaliou as condutas de riscos mais comuns dos consumidores em restaurantes self-service, constatando os maus hábitos dos consumidores, como não higienizar as mãos antes de se servir, o que comprova a falta de hábito e conscientização de grande importância para esta prática. Ao lavar as mãos, remove-se a sujeira e diminui a quantidade de bactérias da pele; ao passar a mão no cabelo, os fios podem carregar grande quantidade de bactérias, fungos e parasitas. E ainda: encostar outras partes do corpo, acessórios e vestimentas contaminadas com micro-organismos presentes no ar e na poeira; falar, tossir ou espirrar sobre o balcão do self service; bem como deixar colheres de uso para se autosservirem caídas dentro dos alimentos - são todos fatores que contribuem para a contaminação do sorvete, que pode ocorrer desde a matéria-prima até a comercialização do produto.

\section{Considerações finais}

Dentre as amostras analisadas todas estavam contaminadas por coliformes totais e termotolerantes, confirmados pela presença de E. coli. Nove amostras apresentaram colônias de Salmonella sp. e nenhuma apresentou fungos psicrotróficos. Cinco das amostras analisadas para coliformes termotolerantes estão fora do limite permitido para a RDC $n^{\circ} 12 / 01^{15}$, que trata de gelados comestíveis.

No contexto geral desta pesquisa, as amostras não apresentam qualidade microbiológica satisfatória, podendo acarretar riscos à saúde dos consumidores. Demonstra-se, assim, a necessidade de evitar a exposição direta dos sorvetes pelo modelo self-service, assim como a adoção de boas práticas de produção, com treinamento para os manipuladores e comerciantes, controlando a higienização e a qualidade da matéria-prima na produção do sorvete. 


\section{Referências}

1. Seolin VJ, Scapim MRS, Pieretti GG, Tonon LAC, Madrona GS. Substituição de açúcar por frutooligosacarídeo em sorvete. Rev. Bras. Tecnol. Agroindustrial 2013; 7(2):1062-73.

2. Agência de Vigilância Sanitária. Regulamento técnico para gelados comestíveis e preparados para gelados comestíveis. Brasilília: ANVISA; 2005.

3. Alves MG, Ueno M. Restaurantes self-service: segurança e qualidade sanitária dos alimentos servidos. Rev. Nutr. 2010; 23(4):573-80.

4. Medeiros LB, Saccol ALF, Delevati MTS, Brasil CCB. Diagnóstico das condições higiênicas de serviços de alimentação de acordo com a NBR 15635:2008. Brazilian J. Food Technol. 2012; 15(spe):47-52.

5. Nörnberg M de FBL, Tondo EC, Brandelli A. Bactérias psicrotróficas e atividade proteolítica no leite cru refrigerado. Acta Sci. Vet. 2009; 37(2):157-63.

6. Parussolo G, Schmit J, Michel PH, Busatto RT, Ries EF, Rosa VP. Avaliação microbiológica de sorvetes comercializados no município de Frederico Westphalen. In: Anais do $12^{\circ}$ Congresso Latinoamericano de Microbiologia e Higiene de Alimentos - MICROAL 2014. Blucher Food Science Proceedings 2014; 1(1). São Paulo: Blucher; 2014. 2 p.

7. Comas e Boff C, Crizel TDM, Araujo RR De, Rios ADO, Flôres SH. Desenvolvimento de sorvete de chocolate utilizando fibra de casca de laranja como substituto de gordura. Ciência Rural 2013; 43(10):1892-7.

8. Boreli K, Brito NJN, Santos ECG, Silva GA. Avaliação de coliformes totais e termotolerantes em bebedouros de escolas públicas e ginásios de esportes em um município do norte de Mato Grosso. REBES Rev. Bras. Educ. e Saúde. 2014; 5(1):96-9.

9. Silva N, Junqueira VCA, Silveira NFA. Manual de métodos de análise microbiológica de alimentos. 2 ed. São Paulo: Varela; 2001.

10. Oliveira ET, Batista PJS, Oliveira EG, Silva ITF, Froehlich A. Avaliação Microbiológica de Sorvetes Comercializados nos Principais Supermercados de Maceió-AL. In: Anais VII CONNEPI; Palmas, 2012.

11. Silveira H, Sampaio Neta N, Pinto R, Rodrigues M, Costa J. Avaliação da qualidade físico-química e microbiológica de sorvetes do tipo tapioca. Rev. Ciência Agronômica 2009; 40(1):60-5.

12. Hoffmann FL, Penna ALB, Coelho AR. Qualidade higiênico-sanitária de sorvetes comercializados na cidade de São José do Rio Preto-SP-Brasil. Rev Hig Alimentar. 2000; 76(11):62-68.

13. Diogo GT, Aguiar GM, Tolentino MC, Buffara D, Pileggi M. Avaliação microbiológica de sorvetes comercializados na cidade de Ponta Grossa - PR e da água usada na limpeza das colheres utilizadas para serví-los. Publ UEPG - Biol Heal Sci. 2002; 8(1):23-32.

14. Shinohara NKS, Barros VB De, Jimenez SMC, Machado E de CL, Dutra RAF, Lima Filho JL. Salmonella spp., importante agente patogênico veiculado em alimentos. Cien. Saúde Colet. 2008; 13(5):1675-83. 
15. Agência de Vigilância Sanitária. Regulamento técnico sobre padrões microbiológicos para alimentos. Brasília: ANVISA; 2001.

16. Esmerino LA, Penteado FR. Avaliação da qualidade microbiológica da carne de frango comercializada no município de Ponta Grossa - Paraná. Publ UEPG Ciências Biol e da Saúde. 2011; 17(1):37-45.

17. Daniel de Paula CM, Casarin LS, Tondo EC. Escherichia coli O157:H7- patógeno alimentar emergente. Vigilância Sanitária em Debate 2014; 2(4):23-33.

18. Cunha FMF, Magalhães MBH, Bonnas DS. Desafios da gestão da segurança dos alimentos em unidades de alimentação e nutrição no Brasil: uma revisão. Context da Aliment - Rev. Comport. Cult e Soc. 2012; 1(2):4-14.

19. Rizzo-Benato RT. Qualidade microbiológica do leite e do sorvete de massa de uma indústria de pequeno porte do município de Piracicaba, SP. São Paulo: Escola Superior de Agricultura Luiz de Queiroz, Universidade de São Paulo; 2004. p. 62.

20. Tonet A, Ribeiro AB, Bagatin AM, Cristina C, Fiori L, Integrado F, et al. Qualidade microbiológica de sorvetes e caldas pasteurizadas produzidos artesanalmente em uma cidade do estado do Paraná. Rev. Bras. Pesq. Alim. 2011; 2(2):96-103.

21. Falcão DP, Salgado Filho G, Nishida NK, Borges SR. Exame microbiológico de sorvetes não pasteurizados. Rev. Saude Pública 1983;10:2-8.

22. Faria M, Oliveira LBD, Costa FE de C. Determinação da qualidade microbiológica de polpas de açaí congeladas comercializadas na cidade de Pouso Alegre, MG. Aliment e Nutr. 2012; 23(2):243-9.

23. Vedovato GM, Bastos DHM, Mancuso AMC, Behrens JH. A scale to evaluate customer attitudes towards food risks in restaurants. Vigilância Sanitária em Debate 2014; 2(4):53-61.

24. Medeiros LB, Pereira LC, Saccol AL de F. Atitudes de risco dos consumidores em self-service. Rev. Inst. Adolfo Lutz 2012; 71(4):737-40.

Recebido: 09/7/2015

Aprovado: 18/10/2015 